Шарабарина Наталия Андреевна

студентка

ФГБОУ ВПО «Петербургский государственный университет путей сообщения Императора Александра І» г. Санкт-Петербург

\title{
ПРОБЛЕМЫ АНАЛИЗА ФИНАНСОВОЙ УСТОЙЧИВОСТИ ПРЕДПРИЯТИЙ
}

Аннотация: в данной статье дается краткое определение финансовой устойчивости организации, описывается актуальность этой категории анализа в нынешних экономических условиях России. Автором перечислень основные этапь её анализа, а также изложены актуальные на сегодняиний день проблемы анализа финансовой устойчивости предприятий и предложен возможный вариант решения одной из основных проблем.

Ключевые слова: финансовая устойчивость, анализ финансовой устойчивости, показатели платежеспособности.

Актуальность проблем анализа финансовой устойчивости организаций обуславливается тем, что в условиях нынешнего кризиса экономики России инвесторы с ещё большей осторожностью будут вкладывать деньги в предприятия. Они захотят вкладывать свои средства в финансово устойчивые предприятия, способные приносить доход. Также и кредитные учреждения будут выдавать кредиты платежеспособным предприятиям с минимальными рисками банкротства. Основой для принятия решений потенциальных вкладчиков и кредиторов является бухгалтерская отчетность, а одними из показателей надежности предприятия будут выступать именно показатели финансовой устойчивости, определяемые на основе бухгалтерского баланса.

Финансовая устойчивость организации - это способность субъекта хозяйствования функционировать и развиваться, сохранять равновесие своих активов 
и пассивов, гарантирующих его постоянную платежеспособность и инвестиционную привлекательность в границах допустимого уровня риска [1].

Для получения адекватных выводов об уровне финансовой устойчивости организации целесообразно пользоваться данными отчетности за 2-3 года [2].

Обычно финансовый анализ проводится в три этапа.

Этап 1. Выбор метода анализа:

- сравнение достигнутого уровня показателей с показателями бизнес-плана, среднеотраслевыми, мировыми и т. д. для оценки результатов бизнеса анализируемой организации;

- сравнение показателей анализируемой организации во времени для оценки динамики ее развития и прогнозирования будущих результатов;

- сравнение показателей анализируемой организации с показателями конкурентов для оценки рыночной устойчивости.

Этап 2. Оценка качества информации и достижение сопоставимости данных финансовой отчетности.

Этап 3. Аналитические процедуры (использование стандартных приемов и методов для преобразования исходных данных, систематизации, интерпретации показателей) [1].

Аналитик сталкивается с проблемой уже на этапе подготовки информации к аналитическим процедурам - зачастую предприятия составляют годовую бухгалтерскую (финансовую) отчетность второпях и впоследствии корректируют её показатели в бухгалтерской отчетности следующего отчетного года, что отражается в пояснениях к ней. На фоне этой проблемы появляется вероятность того, что в отчетности за прошедший отчетный период скрываются неточности и искажения, которые могут привести к соответствующим результатам анализа финансовой устойчивости.

Еще одной проблемой на этапе подготовки данных, которая постепенно уходит на второй план, является вариативность форм отчетности - начиная с годовой бухгалтерской отчетности за 2011 год изменилась форма предоставления отчета, что приводит к неполной сопоставимости данных в годовой отчетности 
за более ранние периоды. Конечно, эта проблема сейчас будет касаться аналитика лишь в случае проведения ретроспективного анализа за 5 и более лет.

Одной же из самых важных проблем анализа финансовой устойчивости хозяйствующего субъекта является вариативность как самих формул расчета показателей финансовой устойчивости, так и границ их нормативных значений. Разные авторы предлагают разные методы расчета одних и тех же показателей, а также различную их классификацию. Рассмотрим вышеописанную проблему на примере показателей платежеспособности предприятия.

Таблица 1

Классификация показателей платежеспособности организаций разными авторами [2-5]

\begin{tabular}{|c|c|c|c|c|}
\hline \multirow[b]{2}{*}{ Автор } & \multirow{2}{*}{$\begin{array}{c}\text { Показатель пла- } \\
\text { тежеспособно- } \\
\text { сти }\end{array}$} & \multicolumn{2}{|c|}{ Формула расчета } & \multirow{2}{*}{$\begin{array}{c}\text { Рекоменду- } \\
\text { емый нор- } \\
\text { матив }\end{array}$} \\
\hline & & Числитель & Знаменатель & \\
\hline \multirow[t]{3}{*}{ Гиляровская Л.Т. } & $\begin{array}{l}\text { Коэффициент } \\
\text { абсолютной лик- } \\
\text { видности }\end{array}$ & ДС + ЦБ & $\begin{array}{l}\text { Краткосрочные } \\
\text { обязательства }\end{array}$ & $0,2-0,5$ \\
\hline & $\begin{array}{l}\text { Коэффициент } \\
\text { критической } \\
\text { ликвидности }\end{array}$ & $\begin{array}{l}\text { ДС + ДЗ+ КФВ + } \\
\text { ПОА }\end{array}$ & $\begin{array}{l}\text { Краткосрочные } \\
\text { обязательства }\end{array}$ & $0,5-1$ \\
\hline & $\begin{array}{l}\text { Коэффициент } \\
\text { текущей ликвид- } \\
\text { ности }\end{array}$ & Оборотные активы & $\begin{array}{l}\text { Краткосрочные } \\
\text { обязательства }\end{array}$ & $1-2$ \\
\hline \multirow[t]{3}{*}{ Шеремет А.Д. } & $\begin{array}{l}\text { Коэффициент } \\
\text { абсолютной лик- } \\
\text { видности }\end{array}$ & ДС + КФВ & $\begin{array}{l}\text { Краткосрочные } \\
\text { обязательства }\end{array}$ & Более 0,2 \\
\hline & $\begin{array}{l}\text { Коэффициент } \\
\text { критической } \\
\text { ликвидности } \\
\end{array}$ & ДС + КДЗ + КФВ & $\begin{array}{l}\text { Краткосрочные } \\
\text { обязательства }\end{array}$ & Более 1 \\
\hline & $\begin{array}{l}\text { Коэффициент } \\
\text { текущей ликвид- } \\
\text { ности } \\
\end{array}$ & $\begin{array}{l}\text { ДС + КДЗ + КФВ + } \\
\text { Запасы + НДС }\end{array}$ & $\begin{array}{l}\text { Краткосрочные } \\
\text { обязательства }\end{array}$ & Более 2 \\
\hline \multirow[t]{3}{*}{ Крылов С.И. } & $\begin{array}{l}\text { Коэффициент } \\
\text { мгновенной лик- } \\
\text { видности }\end{array}$ & $\begin{array}{l}\text { Денежные сред- } \\
\text { ства + денежные эк- } \\
\text { виваленты }\end{array}$ & $\begin{array}{l}\text { Краткосрочные } \\
\text { обязательства } \\
\text { - ДБП }\end{array}$ & $\begin{array}{l}\text { Не менее } \\
0,2\end{array}$ \\
\hline & $\begin{array}{l}\text { Коэффициент } \\
\text { абсолютной лик- } \\
\text { видности }\end{array}$ & $\begin{array}{l}\text { ДС и ДЭ + КФВ (за } \\
\text { искл. ДЭ) }\end{array}$ & $\begin{array}{l}\text { Краткосрочные } \\
\text { обязательства } \\
\text { - ДБП }\end{array}$ & $\begin{array}{l}\text { Не менее } \\
0,3\end{array}$ \\
\hline & $\begin{array}{l}\text { Коэффициент } \\
\text { быстрой ликвид- } \\
\text { ности }\end{array}$ & $\begin{array}{l}\text { ДС и ДЭ + КФВ (за } \\
\text { искл. ДЭ) + КДЗ }\end{array}$ & $\begin{array}{l}\text { Краткосрочные } \\
\text { обязательства } \\
\text { - ДБП }\end{array}$ & $\begin{array}{l}\text { Не менее } \\
0,8\end{array}$ \\
\hline
\end{tabular}




\begin{tabular}{|l|l|l|l|l|}
\hline & $\begin{array}{l}\text { Коэффициент } \\
\text { средней ликвид- } \\
\text { ности }\end{array}$ & $\begin{array}{l}\text { ДС и ДЭ + КФВ (за } \\
\text { искл. ДЭ) + КДЗ } \\
\text { Запасы }\end{array}$ & $\begin{array}{l}\text { Краткосрочные } \\
\text { обязательства } \\
- \text { ДБП }\end{array}$ & $\begin{array}{l}\text { Не менее } \\
1,2\end{array}$ \\
\cline { 2 - 5 } & $\begin{array}{l}\text { Коэффициент } \\
\text { текущей ликвид- } \\
\text { ности }\end{array}$ & Оборотные активы & $\begin{array}{l}\text { Краткосрочные } \\
\text { обязательства } \\
- \text { ДБП }\end{array}$ & Не менее 2 \\
\hline
\end{tabular}

Пояснения: ДС - денежные средства; ДЭ - денежные эквиваленты; ЦБ ценные бумаги; ДЗ - дебиторская задолженность; КДЗ - краткосрочная дебиторская задолженность; КФВ - краткосрочные финансовые вложения; ПОА - прочие оборотные активы; НДС - налог на добавленную стоимость; ДБП - доходы будущих периодов.

Таким образом, можно выявить еще одну общую для анализа в целом проблему - отсутствие единой системы показателей, характеризующих состояние предприятий, функционирующих в одной отрасли. Данная проблема приводит к тому, что различные методики, применяемые при анализе предприятий, затрудняет сравнение результатов их хозяйственной деятельности в конкретный момент времени по причине того, что для достижения сравнимости полученных показателей могут понадобиться дополнительные расчеты.

Однако многие аналитики делают упор на выявление тенденции в развитии предприятия, пренебрегая сравнением показателей деятельности в пространстве, хотя этот метод позволяет вывить преимущества конкурентов в том или ином аспекте хозяйственной деятельности. Особенно важность такого подхода возрастает в условиях кризиса экономики, когда необходимо более оперативно реагировать на изменение внешней среды.

Вышеизложенные проблемы обосновывают потребность в выпуске соответствующими ведомствами Российской Федерации рекомендаций по отдельным отраслям экономики (например, рекомендации для торговой отрасли может издать Министерство промышленности и торговли РФ) с указаниями формул и нормативных значений показателей, с помощью которых хозяйствующие субъекты смогут самостоятельно оценить свое текущее финансовое состояние и возможные финансовые риски, а также сравнить полученные результаты как с прямыми конкурентами, так и с предприятиями-лидерами отрасли. 


\section{Список литературы}

1. Вахрушина М.А. Анализ финансовой отчетности / М.А. Вахрушина, Н.С. Пласкова. - М.: Вузовский учебник, 2009. - 367 с.

2. Гиляровская Л.Т. Комплексный экономический анализ хозяйственной деятельности: Учеб. / Л.Т. Гиляровская, Д.В. Лысенко, Д.А. Ендовицкий. - М.: Велби; Проспект, 2008. - 360 с.

3. Шеремет А.Д. Комплексный анализ хозяйственной деятельности: Учеб. пособие / А.Д. Шеремет. - М.: ИД РИОР, 2009. - 255 с.

4. Крылов С.И. Анализ бухгалтерского баланса коммерческой организации с помощью финансовых коэффициентов / С.И. Крылов, Б.Н. Ельцина // Финансовый вестник: финансы, налоги, страхование, бухгалтерский учет. - 2013. №8 // Справочная правовая система «КонсультантПлюс» [Электронный ресурс]. - Режим доступа: http://www.consultant.ru 